\title{
The Influence of Logical Positivism on Nursing Practice
}

Ann L. Whall

While logical positivism has been said to have had major influence on the development of nursing theory, whether this influence pervades other aspects of the discipline has not been discussed. One central aspect of logical positivism, the verificationist perspective, was used to examine texts, curricular guides and standards of practice that guided nursing practice in the decades in which logical positivism had influence on nursing theory construction. This review of the literature does not support the influence of logical positivism, as exemplified by the verificationist perspective, on nursing practice guidelines.

Scrooge retired early on the evening before Christmas. When the first spirit appeared to him, one Jacob Marley, Scrooge doubted Marley's existence. Marley said to Scrooge, "Why do you doubt your senses?" Scrooge replied that he did so because the senses are so easily affected. Scrooge suggested that Marley's appearance might be the result of indigestion brought on by an underdone potato or slightly tainted food.

In this scene from $A$ Christmas Carol, Dickens alludes to one of the central issues in philosophy of science, to wit, how we know what we know, and what counts for proof of what we know. Various schools of philosophy have debated this issue for many years.

The views of philosophy of science, it has been argued, have influenced all attempts "to know" (Polkinghorne, 1983). Thus attempts of nursing to structure its body of knowledge may understandably have been influenced by values represented by the prevailing philosophy of science. This paper examines the influence of the logical positivist perspective on one type of nursing knowledge-the guidelines for nursing practice found in the period between the 1950 s and 1970s. It was during these decades that logical positivism was described as having its greatest influence on the development of nursing theory (Suppe \& Jacox, 1985).

There are several premises on which this paper is based. The first premise is that philosophy of science informs or influences the development of nursing knowledge, just as it informs all knowledge development efforts; this is opposite of the position that philosophy of science is an outcome of these efforts. Secondly, Ellis' (1984) position is accepted regarding the nature of science in nursing. Ellis stated that science is comprised of both the products and the processes of our attempts "to know." The processes are seen as the discussions and arguments regarding the products of the discipline.
Science is thus comprised of processes such as research examinations as well as philosophic inquiries. The scientific products are, in this view, the outcomes of these processes. Such products as theory as well as nursing practice guides are thus scientific products of our discipline. In this sense nursing practice is a product of the scientific processes-not "more" than science itself.

A final premise on which this paper is based is that by examination of practice guidelines we may infer conclusions regarding the nature of nursing practice itself. The validity of this conclusion is always open to further examination and might be one outcome of this discussion. Because this paper is, however, an initial attempt to examine the influence of logical positivism on nursing practice guidelines, it stops short of examination of practice itself and leaves this question for others to pursue.

\section{The Influence of Logical Positivism on Nursing}

It is important to realize that the field of logical positivism is much too broad to be useful in any one examination of nursing practice guidelines. Several major tenants of logical positivism were examined for this paper; and in each case logical positivists were found who would deny each of the tenants. This variability forced the focus on one specific aspect of logical positivistic view, i.e., the verificationists' perspective, generally held to be reflective of the original Vienna Circle of philosophers (Flew, 1979).

The important discussion of Jacox and Webster (1986), concerning logical positivism serves as a beginning point for this discussion. Jacox and Webster pointed out that a prior paper of Jacox's (1974) assumed certain tenants of logical positivism, and suggested that other nursing theory development discussions at that time also reflected an implicit logical

ANN L. WHALL, R.N., Ph.D., F.A.A.N. Lambda, is Professor and Director, Center for the Development of Gerontological Nursing, University of Michigan, School of Nursing, 400 North Ingalis Building, Ann Arbor, MI 48109. The author recognizes Peter Railton, Ph.D., Associate Professor of Philosophy. University of Michigan, and Margaret Calarco, doctoral student, the University of Michigan. School of Nursing, who reviewed and made suggestions on the manuscript. A major portion of this paper was presented to the Doctoral Nursing Forum, Tucson, AZ on June 16, 1988. Correspondence to 400 North Ingalls Building, Ann Arbor, MI 48109

Accepted for publication March 15, 1989. 
positivist view. The authors also reported that this view had already been rejected by a large number of philosophers of science. According to Jacox and Webster (1986), opponents of the logical positivism position called it the "received view." Critics objected to the control of key journals and departments in academe by those holding this view. This group dominated the philosophy of science thought in the 1930 s through the $1950 \mathrm{~s}$, and its influence in nursing was seen in the 1950s through the 1970s. Thus the criticisms of logical positivism were not reffected in the discussions on nursing theory of the $50 \mathrm{~s}$ through $70 \mathrm{~s}$, and some of the discussions and resultant theories were rooted in this logical positivistic pre-1960s notion of science (Jacox \& Webster, 1986).

The following is a description of the aspect of logical positivism, or the verificationist perspective of the Vienna Circle, which was used to examine the nursing practice guidelines for this paper. The meaning of a proposition consists in its method of verification. Since propositions about creation could not be observed, they were not verifiable and thus meaningless. Arguments pro/con phenomena that were not observable were pointless. Statements about things that were perhaps less observable, like those of ethics and aesthetics, were seen more as statements of emotional attitudes (Flew, 1979 , p. 214).

The outcome of this perspective is the de-valuing of introspective data such as those pertaining to spirituality and/or feelings as well as the belief that intrusion of values into science results in a distortion of knowledge.

\section{Review of the Curricular Guides, Standards of Practice and Textbooks}

In order to examine the influence of the VERIFICATIONIST perspective upon nursing practice guidelines during the time when Jacox and Webster (1986) posited the influence of logical positivism was the greatest, literature from the 1940 s through 1970 s was reviewed. Ellis inferred that nursing textbooks, curricular guides and Standards of Practice are important nursing practice guidelines, in that they address what nurses "fix, alter, or maintain" (quoted in Pressler \& Fitzpatrick, 1988).

\section{Curricular Guides}

The curricular guide with the most relevance for the $1940 \mathrm{~s}$ is $A$ curriculum guide for schools of nursing (1937) published and authored by the National League for Nursing Education (NLNE). The guide states at the outset that the aims and methods used in nursing were to be "in harmony with the principles of modern science" (p. 16). Nurses were thus "to have access to technical knowledge which was a result of scientific investigations"' (p. 16).

However, lest one assume that this meant acceptance of the strict verificationist perspective, students were to unite this knowledge with their knowledge of ethical, aesthetic and spiritual aspects of the care of patients. Although these terms were not defined, the advisory panel feared that the process of adjustment (by students to nursing) might neglect spiritual and other aspects of their personality development. There was also a concern that nurses make the environment of patients more fit for "human living" (p. 19). The Guide warned that one of the most severe criticisms nursing had to meet was subordination of the human aspect (of patients) to technical considerations (p. 21). A categorization of the detailed activities of nursing also suggested a valuing of introspective data.

This guide thus put forth a view that was opposed to that of the strict verificationist perspective. Whether spirituality and emotions were viewed the same way in 1937 as they are today is a subject for historical research. Use of these terms, however, supports a lack of a strict verificationist perspective in these guidelines. This was the last curriculum guide to be published by the NLNE.

A textbook that guided the teaching of clinical practice principles during the 1950s and later was Heidgerkin's Teaching in Schools of Nursing: Principles and Methods (2nd Edition, 1953). In the Philosophy and Science section it was pointed out that the physical sciences had left their imprint on the twentieth century and that many scientists felt that through the physical sciences they could discover the meaning of life. It was concluded, however, that science could not give a satisfactory conceptualization of life (p. 23). DeHovre-Jordan, a philosopher of education, was quoted as stating that life demands judgments of value and that the then present generation had "lost its bearing and seeks them in vain in the time-table of modern science" (p. 24). This textbook guide to curriculum development was thus not rooted in the verificationist perspective or in that which sought to be value free and not dependent on introspective considerations.

A later guideline for nursing practice, the American Nurses' Association (ANA) Standards for Nursing Education (1975), listed several assumptions regarding the mission of nursing. This mission was seen as the knowledgeable assessment of all individuals and the humane, artistic application of nursing knowledge (p. 3). Ethics were described as being foundational to nursing. Nursing science was defined as the structured body of verified knowledge as well as humane practice. Throughout this ANA publication there is a dual focus on verifiability as well as on the value of ethics and artistic application.

The Standards of Medical-Surgical Nursing Practice (ANA, 1974) identified the focus of nursing as the care of persons with known physiological alterations. These standards appeared somewhat less emphatic in terms of a focus on introspective data and the valuing of aesthetics than the other standards. The Standards of Psychiatric and Mental Health Nursing Practice (ANA, 1973c), however, begins with a statement that this speciality employs theories of behavior as its scientific base, but that this is combined with knowledge of and positive use of self as the art of this specialty. Terms such as "therapeutic relationship," "therapeutic milieu" and "art as well as science" suggest that introspective data is essential to nursing practice.

The Standards of Maternal and Child Health Nursing Practice (ANA, 1973b) defined nursing as a dynamic process, goal directed toward the needs of individuals and families during health and illness. A major premise was the dignity of individuals and families and a valuing of the personal meanings of these persons. The Standards of Community Health Nursing Practice (ANA, 1973a) were also reviewed. The systematic and continuous collection of data was emphasized on such patient parameters as emotions and perceptions. Mutuality between the nurse and client was suggested as well as meaningfulness not necessarily requiring testability.

None of the above guides or standards, therefore, suggested a strict verificationist perspective or the denial of the 
place that values play in science. In these standards the values of society were seen as being important to nursing practice, while aesthetic and ethical knowledge was seen as being vital. Because of a less clear focus on introspective data in the ANA's medical-surgical standards, texts representative of medical-surgical nursing from the 1940 s through the 1970 s were also reviewed. These texts were selected on the basis of reference to them in card catalogues as well as in other nursing texts.

Harmer and Henderson (1939) discussed the feelings of tolerance and sympathy as being essential to nursing practice. Throughout the text the importance was stressed of the patients and nurse's emotions as a meaningful consideration in practice.

One textbook cited in several places was the Essentials of medicine: The basis of nursing care, published originally in 1908 (Emmerson \& Taylor, 1950). The eighth through thirteenth editions had a nurse as author, second to a physician. As in all the texts that follow, the section on definitions of nursing and the underlying assumptions about nursing was reviewed. The scope of nursing practice was described as being much more than the conduct of technical maneuvers. The text cautioned against drawing a sharp distinction between subjective and objective data, stating that both were interrelated and important. The approach thus supported both objective testing and sense experience and placed an emphasis on subjective data. A clear verificationist view was not present.

Nordmark and Rohweder (1959) discussed internal communications, expressions of feelings and emotions and the need to respect personal beliefs. Again, these positions would be contrary to a strict verificationst perspective. In the preface to Shafer, Sawyer, McCluskey and Lifgren (1958), the need is discussed for nurses to evaluate their own feelings and emotions as well as the feelings of patients.

The Lippincott Manual of Nursing Practice (Brunner et al., 1974) was reviewed. Again, emotions and feelings of patients and other types of introspective data were discussed as a concern for nursing. Beland and Passos (1975) defined clinical nursing as having to do with the observation and treatment of patients. An underlying belief was that persons are spiritual beings with spiritual as well as physical needs and thus this type of data had relevance for nursing practice.

This literature review suggests that the guidelines of practice (i.e., curricular guides, standards of practice and textbooks) do not support undue influence of the verificationist's perspective during the decades when this position purportedly had its greatest influence on nursing theory. There appears to have been a continuing thrust toward including values as a vital part of nursing science as well as emotions and other subjective data as being very important in nursing practice. There were also many discussions of the role that values played in effective nursing practice and of ethical knowledge and values as having great meaning for nursing practice.

\section{Conclusion}

Carper (1978) suggested that there are ethical, personal, aesthetic and empirical ways of knowing. Although the meaning of each "way of knowing" is still being discussed, Carper cautioned that being tied to only one way of knowing is not sufficient for nursing as a professional discipline. There are other current discussions that demonstrate this commitment in nursing to the use of introspective data. Benner's (1984) presentation of the ways to develop expert nursing practitioners suggests that personal knowledge is vital to these efforts and that effective nursing practice makes use of intuitive knowledge.

Aesthetic, personal ways of knowing and ethics were seen by the verificationists as not being meaningful to science (Flew, 1979). Nursing appears traditionally to have valued these types of knowledge, for example, therapeutic use of self and the willingness to consider moral and ethical issues. These are all personal, ethical and aesthetic ways of knowing.

The conclusion is drawn that the practice guidelines were never greatly influenced by the logical positivistic position. If this conclusion holds, the reasons why one scientific product, nursing theory, versus another scientific product, the practice guidelines, should be so differently influenced is a subject for further examination. Nursing scholars must continue the scientific process of discussion about these products. Perhaps one conclusion to draw is that our scientific debates should take note of the effect of philosophy of science on specific aspects of nursing, lest undue and unintended influence take place. Perhaps if a heavy influence of logical positivism on nursing practice had been accepted, nursing might have denied the data it had traditionally seen as important.

\section{References}

American Nurses' Association (1973a). Standards of community health nursing practice. Kansas City: ANA.

American Nurses' Association (1973b). Standards of maternal and child health nursing practice. Kansas City: ANA.

American Nurses' Association (1973c). Standards of psychiatric and mental health nursing practice. Kansas City: ANA.

American Nurses' Association (1974). Standards of medical-surgical nursing practice. Kansas City: ANA.

American Nurses' Association (1975). Standards for nursing education. Kansas City: ANA.

Beland, I., \& Passos, J. (1975). Clinical nursing: Pathophysiological and psychosocial approaches, 3rd. ed. New York: Macmillan Publishing Co.

Benner, P. (1984). From novice to expert: Excellence and power in clinical nursing practice. Menlo Park: Addison-Wesley.

Brunner, L., Suddarth, D., Faries, B., Galligan, K., Lavoie, D. \& Schwalenstocker, A. (1974). The Lippincott manual of nursing practice. Philadelphia: J. B. Lippincott.

Carper, B. A. (1978). Fundamental patterns of knowing in nursing. Advances in Nursing Science, 1(1), 13-23.

Ellis, R. (1984). Theory development in nursing: The state of the art. In proceedings of "Nursing Theories: Sharing for Success"; paper presented at the 50th Anniversary Celebration at Sir Mortimer Davis Jewish General Hospital, Canada, October $3,1984$.

Emmerson, C., \& Taylor, J. (1950). Essentials of medicine: The basis of nursing care. Philadelphia: J. B. Lippincott.

Flew, A. (1979). A dictionary of philosophy. Rev. 2nd ed. (pp. 213-214). New York: St. Martin's Press.

Harmer, B., \& Henderson, V. (1939). Textbook of the principles and practice of nursing. New York: The Macmillan Co.

Heidgerkin, L. (1953). Teaching in schools of nursing: Principles and methods. Philadelphia: J. B. Lippincott.

Jacox, A. (1974). Theory construction in nursing: An overview. Nursing Research, 23, 4-13.

Jacox, A., \& Webster, G. (1986). Competing theories of science. In L. Nicoll (Ed.), Perspectives on nursing theory (Pp. 333, 335-341). Boston: Little Brown.

National League for Nursing Education (1937). A curriculum guide for schools of nursing. New York: NLNE.

Nordmark, M., \& Rohweder, A. (1959). Science principles applied to nursing: A reference for nurse educators. Philadelphia: J. B. Lippincott.

Polkinghorne, D. (1983). Methodology for the human sciences: Systems of inquiry. Albany, NY: State University of New York Press.

Pressler, J., \& Fitzpatrick, J. (1988). Contributions of Rosemary Ellis to knowledge development for nursing. Image, 20(1), 28-30.

Shafer, K., Sawyer, J., McCluskey, A., \& Lifgren, E. (1958). Medical-surgical nursing. Si. Lou is: The C. V. Mosby Co.

Suppe, F., \& Jacox, A. (1985). Philosophy of science and the development of nursing theory. Annual Review of Nursing Research, 3, 241-267. 